\title{
RESEARCHPAPER
}

\section{Studies on agro-chemicals for lodging management in wheat (Triticum aestivum L.) for higher productivity}

\author{
PANKAJ PRAJAPAT ${ }^{1}$, RAMESH CHOUDHARY ${ }^{1}$ AND BHANWAR LAL JAT ${ }^{2}$
}

\author{
${ }^{1}$ Department of Agriculture, Bhagwant University, AJMER (RAJASTHAN) INDIA \\ ${ }^{2}$ Department of Agricultural Biotechnology, Bhagwant University, AJMER (RAJASTHAN) INDIA \\ Email : kripa38156@gmail.com
}

Article Info : Received : 01.06.2017; Revised : 12.08.2017; Accepted : 09.09.2017

\begin{abstract}
Aberrant weather conditions prevailing in the last few years increased the threat of wheat lodging which is a limiting factor for higher productivity and thus, lodging management is very important to sustain and achieve higher wheat yields. Keeping this in view, two studies were conducted to manage lodging in wheat by evaluating agro- chemicals. Experiment I consisted of 12 treatments laid in Factorial Randomized Block Design with three replications having four NPK doses and three growth regulators, NGR, GR1 and GR2. Results revealed that RDF resulted in more tiller $/ \mathrm{m}^{2}$, shoot: emergence ratio, increased plant height, increased dry matter but these growth parameters were at par with SSNM-7 and SSNM-8. RDF resulted in minimum lodging angle, area lodged per cent and lodging score, highest grain yield and highest harvest index, maximum gross return, net returns and B: C, maximum nitrogen and phosphorus uptake by grain. Whereas potassium uptake was highest under SSNM-8. Nutrient doses above RDF favoured the wheat lodging. GR2 resulted in higher emergence, higher tiller $/ \mathrm{m}^{2}$, lower mortality percentage, higher dry matter production, higher leaf area index, higher 1000 grain weight. However, plant height and internode length was minimum in GR1.Grain yield and harvest index was higher in GR1. Interaction effects for lodging observation revealed that RDF with GR1 resulted in lower lodging angle, area per cent lodged and lodging score. RDF with GR2 resulted in higher 1000 grain weight. Grain yield and harvest index was highest in RDF with GR1. In experiment-2 lodging was induced manually at grain filling stage by dragging a rope over plot to evaluate the effect of agro-chemicals on recovery ability of induced lodged wheat. This experiment consisted of five treatments as RDF+WL, RDF+IL, RDF+IL+ ethrel, RDF+IL+KC1 and RDF+IL+nano-silicon. Results revealed that tiller $/ \mathrm{m}^{2}$, shoot: emergence ratio, plant height was not affected by treatments. Dry matter, leaf area index, peduncle length, internode length, days taken to physiological maturity was highest in RDF+WL. Lodging angle, area per cent lodged and lodging score was minimum in RDF + nano-silicon. 1000 grain weight was maximum in RDF+WL which was at par with RDF+IL+ nanosilicon. Grain yield, biological yield, straw yield and harvest index was highest in RDF+WL. Gross return, net return, benefit: cost ratio was highest in $\mathrm{RDF}+\mathrm{WL}$. Ethrel, $\mathrm{KC1}$ and nano- silicon have recovered the wheat from induced lodging, but nano-silicon was more effective in recovering from artificially induced lodging. However, these chemicals did not recover the crop fully and yield was still much lower than RDF + WL. From this study it can be concluded that RDF along with cycocel should be recommended for wheat crop to minimize the crop lodging and thus, produce more grain yield.
\end{abstract}

Key words : NPK, SSNM-7, SSNM-8, Nano-silicon, NGR

How to cite this paper : Prajapat, Pankaj, Choudhary, Ramesh and Jat, Bhanwar Lal (2017). Studies on agro-chemicals for lodging management in wheat (Triticum aestivum L.) for higher productivity. Asian J. Bio. Sci., 12 (2) : 134-155.DOI : 10.15740/HAS/AJBS/12.2/134-155. 